Case Reports
in Dermatology

\title{
An Intriguing Case of Ectopic Benign Migratory Glossitis Resembling Secondary Syphilis: A Case Report
}

\author{
Corolina Leone Norberto Sugaya Dante Migliari \\ Department of Stomatology, Oral Medicine Clinic, School of Dentistry, University of \\ São Paulo, São Paulo, Brazil
}

\section{Keywords}

Oral lesions · Benign migratory glossitis · Ectopic · Differential diagnosis

\begin{abstract}
Oral mucosal lesions presenting as erythematous patches usually pose difficulties for a clinical diagnosis. They elicit an array of differential diagnosis that mainly includes oral candidosis, contact mucosal reaction, oral lichenoid lesion, oral psoriasiform, autoimmune disease, and, not to forget, secondary syphilis. In this present case, all those above-mentioned possibilities were ruled out, while secondary syphilis stood as the main diagnosis. As this was also later excluded by a negative serological treponemal test, the final diagnosis rested on an ectopic manifestation of benign migratory glossitis (BMG), whose diagnosis was based on the clinical aspects of the lesions, along with their spontaneous disappearance in a short period of time (a hallmark of this condition) and the presence of fissured tongue, a manifestation that occurs very often in concomitance with BMG.

\section{Introduction}

As its own name reveals, benign migratory glossitis (BMG) is an oral change that occurs on the tongue, with its diagnosis being made almost invariably on a clinical basis. However, in some rare instances, BMG arises in other areas of the oral mucosa as an ectopic manifestation, and, in this circumstance, it may pose some difficulties for its proper diagnosis [1-3].

Dante Migliari
Departamento de Estomatologia, Faculdade de Odontologia, Universidade de São Paulo
Av. Prof. Lineu Prestes, 2227, Cidade Universitária
São Paulo, SP 05508-000 (Brazil)
damiglia@usp.br




\section{Case Reports in Dermatology}

This article reports such a case, in which the clinical aspects of the lesions mostly resembled those of a secondary syphilis, which, later, was ruled out by serologically testing the patient, leading to a possible diagnosis of an ectopic BMG.

\section{Case Report}

A 38-year-old male was referred to our clinic for evaluation of symptomless lesions on his soft-palate mucosa. Oral examination showed erythematous patches in a circinate pattern surrounded by slightly raised yellowish striae (Fig. 1a). Additionally, the patient also presented fissured tongue. His medical history of relevance was that of a brief exposure to cocaine and marijuana during his youth. Otherwise, he was a healthy person.

On the diagnosis approach, the lesions strongly resembled a secondary syphilis because of their morphology showing erythematous patches of plaque-like type. Other possible diagnoses were thought of but ruled out such as trauma, mucosal contact reaction, oral psoriasiform lesion, erythematous candidosis, and autoimmune disease. Despite the patient's denial of any risk behavior that could have led him to being exposed to a sexually transmitted disease, a serological treponemal test was deemed necessary in order to make sure that the diagnosis was confirmed or excluded on an irrefutable basis. Fortunately, the test resulted negative, and upon his returning to our clinic, 3 weeks later, the lesions had already disappeared (Fig. 1b). The final diagnosis was then changed to an ectopic BMG. To support this diagnosis, these findings stood out: (1) the lesion's clinical aspect, i.e., the presence of circinate erythematous patches surrounded by a discrete yellowish stria, (2) the disappearance of the lesion in a short period of time, which is a typical characteristic of this condition, and (3) the presence of fissured tongue (Fig. 2), a finding also commonly seen in combination with BMG in nearly $50 \%$ of cases $[2,3]$.

\section{Discussion}

There are different names for BMG including geographic tongue, geographic stomatitis, and erythema migrans. Whichever term chosen, most important is that BMG is not a real pathology, but, rather, a common idiopathic condition that affects $1-3 \%$ of the population worldwide $[2,4,5]$. The lesion is typical on the tongue, showing a characteristic of erythematous circinate patches with depapillation of the filiform papillae (the fusiform papilla remains unchanged) surrounded by slightly raised yellowish stria. In addition, BMG usually shows a transitory clinical course, disappearing and reappearing from time to time. Its diagnosis is made on a clinical basis, rarely is a biopsy necessary to confirm the clinical findings. Further, the patient should be reassured of the benign characteristic of this condition as there is no effective treatment for BMG, apart from instructing patients to avoid spicy food as they may cause some discomfort while eating.

The present case had caused some difficulty to reach a final diagnosis. The presentation of the lesions could be easily mistaken for a manifestation of secondary syphilis. There is common knowledge among clinicians that oral lesions presenting as erythematous isolated patches or in combination with erosions, serpiginous or circinate rash, or also as multiple white mucous patches, should always be under suspicions of secondary syphilis once other diagnoses had been excluded. When facing that situation, and for precaution, the serological test for syphilis is requested to avoid missing a diagnosis of a disease that can go into a latent

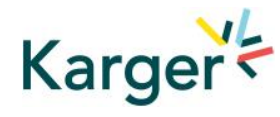




\section{Case Reports in Dermatology}

Case Rep Dermatol 2020;12:262-265

DOI: $10.1159 / 000510776$

(c) 2020 The Author(s). Published by S. Karger AG, Basel www.karger.com/cde

Leone et al.: An Intriguing Case of Ectopic Benign Migratory Glossitis Resembling Secondary Syphilis: A Case Report

form if left untreated. It is important to bear in mind that the stigma made for syphilis as the greater imitator of several mucocutaneous diseases still stands [5].

Finally, the only possible diagnosis for this case was that of an ectopic BMG. To elaborate a hypothetical scenario on which the lesions had not disappeared, the normal procedure would be to perform a biopsy under other diagnoses that would include oral lichenoid and oral psoriasiform lesion [6, 7].

\section{Statement of Ethics}

We, the authors, openly state that this case report was conducted in accordance with the World Medical Association Declaration of Helsinki; additionally, that after the clinical management of the case had been concluded, the patient was informed about the authors' purpose to send his clinical data (including images) for a possible scientific publication, to which he has formally agreed and authorized it by signing a written informed consent.

\section{Conflict of Interest Statement}

The authors have no conflicts of interest to declare.

\section{Funding Sources}

The authors state that there was no external funding source for the preparation of the manuscript. All the available sources were provided by the authors themselves.

\section{Author Contributions}

Caroline Leone: This author has collected the data and made the clinical follow-up. Norberto Sugaya: This author has helped writing the case report and provided insight for its differential diagnosis. Dante Migliari: This author has written and edited this case report apart from searching for the pertinent literature related to this clinical case to properly discuss and address its importance.

\section{References}

1 Zadik Y, Drucker S, Pallmon S. Migratory stomatitis (ectopic geographic tongue) on the floor of the mouth. J Am Acad Dermatol. 2011 Aug;65(2):459-60.

2 Campana F, Vigarios E, Fricain JC, Sibaud V. Geographic stomatitis with palate involvement. An Bras Dermatol. 2019 Oct;94(4):449-51.

3 van der Wal N, van der Kwast WA, van Dijk E, van der Waal I. Geographic stomatitis and psoriasis. Int J Oral Maxillofac Surg. 1988 Apr;17(2):106-9.

4 Joseph BK, Savage NW. Tongue pathology. Clin Dermatol. 2000 Sep-Oct;18(5):613-8.

5 Sakthivel P, Kakkar A, Sharma SC, Panda S. Mucocutaneous Secondary Syphilis: 'The Great Imitator'. Am J Med. 2018 Feb;131(2):e57-8.

6 Zhu JF, Kaminski MJ, Pulitzer DR, Hu J, Thomas HF. Psoriasis: pathophysiology and oral manifestations. Oral Dis. 1996 Jun;2(2):135-44.

7 Bruce AJ, Rogers RS 3rd. Oral psoriasis. Dermatol Clin. 2003 Jan;21(1):99-104.

\section{Karger'=}




\section{Case Reports in Dermatology}
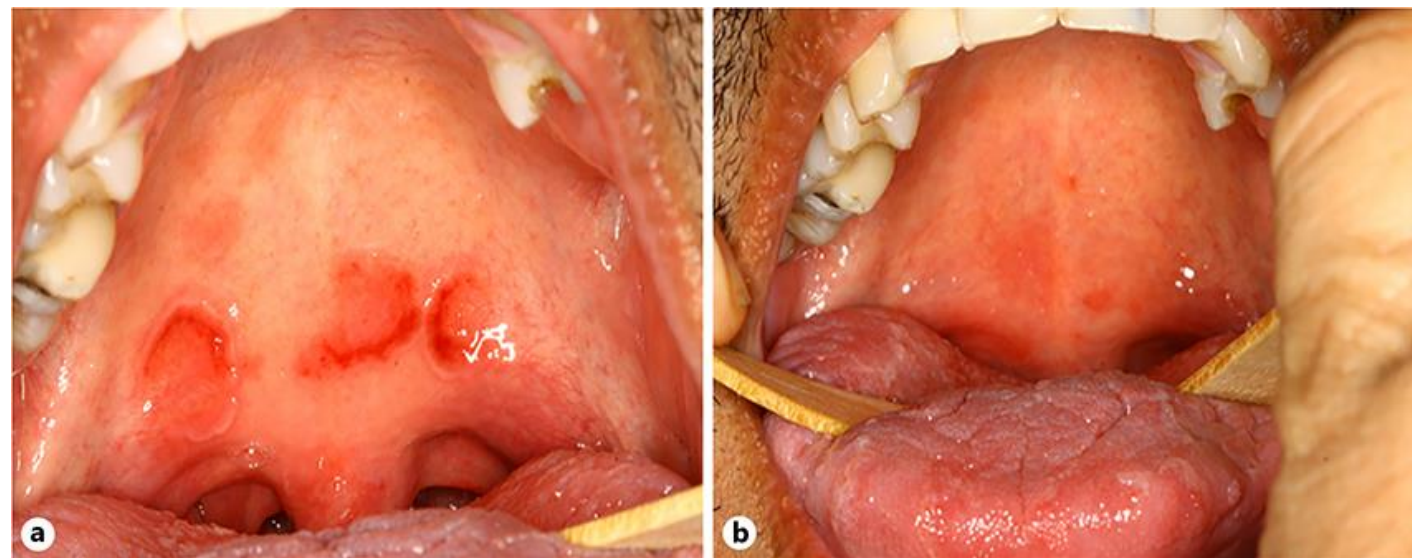

Fig. 1. a Multiple erythematous patches in circinate pattern on the soft-palate mucosa. b Complete remission of the lesions after 21 days since presentation.

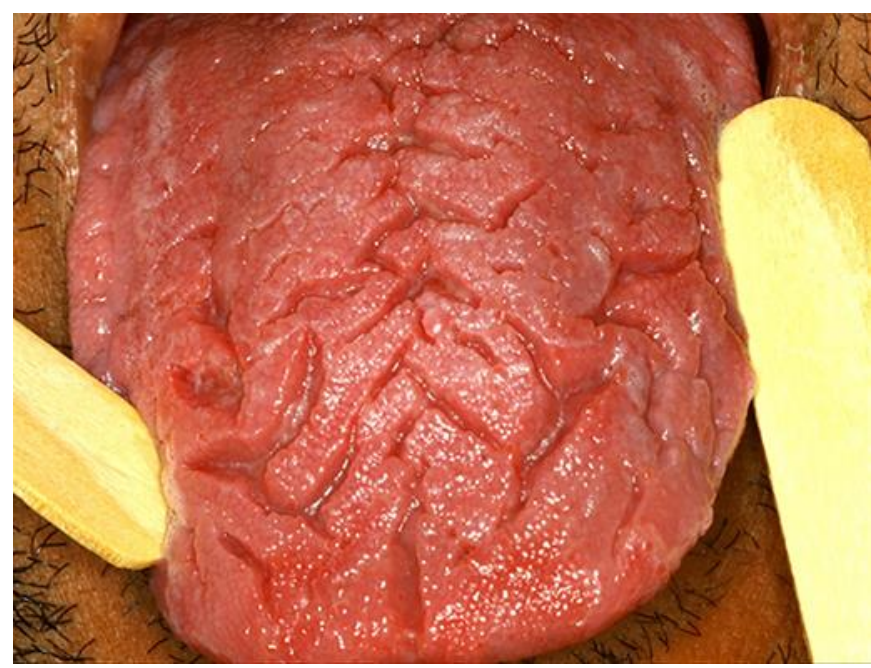

Fig. 2. Fissured tongue also observed in this case. 